\section{A rare case of primary tuberculosis infection with concurrent pleomorphic adenoma of the parotid gland}

\author{
Hassan Al Bisher \\ Department of General Surgery, King \\ Fahd University Hospital, University \\ of Dammam, Dammam, Saudi Arabia
}

\section{Abstract}

Coexistence of parotid tuberculosis along with a benign parotid tumor is a rare entity with only nine cases reported in the literature. We report here a case of primary parotid tuberculosis with concurrent pleomorphic adenoma in a 51-year-old female.

\section{Introduction}

Primary parotid tuberculosis is rare and seldom seen with a benign parotid tumor Tuberculosis is the world's second most common cause of death from infectious disease after HIV/AIDS. ${ }^{1}$ Head and neck tuberculosis represents approximately $15 \%$ of all mycobacterial infections. ${ }^{2,3}$ Tuberculosis of the parotid gland is quite unusual and comprises $1.8 \%$ of head and neck tuberculosis. ${ }^{4}$ The first case of parotid tuberculosis was described by von Stubenrauch in $1894 .{ }^{5}$ Fewer than 200 cases of parotid tuberculosis have been reported in the literature since then ${ }^{6,7}$

\section{Case Report}

A 51-year-old female presented with a painless right parotid mass of four year's duration. The mass became enlarged and painful two weeks prior to her visit in our department. She had no other relevant symptoms and no history of contact with tuberculosis. A physical examination revealed a tender, $2 \times 2 \mathrm{~cm}$ mass in the right parotid region, not attached to the skin, and without facial nerve involvement or cervical lymphadenopathy. The chest examination and X-ray were normal. An investigation of complete blood count, electrolytes, and erythrocyte sedimentation rate were within normal limits. The tuberciline test and polymerase chain reaction (PCR) analysis for mycobacterial tuberculosis were not done because parotid tuberculosis was not suspected before surgery. The CT scan of the right parotid gland (Figure $1 \mathrm{~A}$ and $\mathrm{B}$ ) showed a heterogeneous mass with no calcification; the left parotid gland was normal. The right parotid sialogram was normal (Figure 2). Fine needle aspiration cytology (FNAC) was negative for malignant cells; occasional clumps of epithelial cells with inflammatory cells (polymorphs) and macrophages were found but the acid fast stain was negative. The preoperative diagnosis was benign parotid gland tumor.

A right superficial parotidectomy was performed and the patient had an uneventful postoperative period. The intraoperative finding showed semisolid caseous material within the solid mass. The mycobacterial tuberculosis culture of this material was positive and sensitive to ethambutole, isoniazid, rifampicin, and streptomycin. The histopathological report for the solid mass was suggestive of pleomorphic adenoma. Anti-tuberculosis chemotherapy was started and continued for nine months. The patient was followed up for one year after the superficial parotidectomy and the anti-tuberculosis chemotherapy was satisfactory.

\section{Discussion}

Tumors of salivary gland origin are rare and account for less than $3 \%$ of all neoplasms. Approximately $80 \%$ of tumors of salivary gland origin arise from the parotid gland, and $80 \%$ of these are benign. Approximately $60-90 \%$ of the benign parotid neoplasms are pleomorphic adenoma. ${ }^{6}$ In our case, the clinical impression was of benign parotid tumor and thus superficial parotidectomy was done.

Primary parotid tuberculosis is extremely rare. Two pathways of infection are described in the literature for parotid gland tuberculosis. The first pathway considers that the mycobacterium ascends into the salivary gland via its duct or passes to its associated lymph nodes via the lymphatic drainage. ${ }^{5,9}$ The second pathway involves hematogeneous or lymphatic spread from a distant primary lung focus. ${ }^{8,9}$ Two forms of parotid tuberculosis have been described as diffuse and circumscribed. The diffuse form is the most common and consists of small and large caseous areas or abscesses of edematous, indurated, friable parotid tissue. The circumscribed form is very rare and it may take the form of a cold abscess or of a cyst, ${ }^{5,7}$ as was demonstrated in von Stubenrauch's case, and it is a purely local affection.

The diagnosis of parotid tuberculosis in the majority of reported cases is based on histopathological examination of the surgically removed parotid mass, and these excised tissue specimens commonly were not sent for culture for mycobacterial tuberculosis. ${ }^{9}$ The gold standard in diagnosis remains clinical examination, combined with direct microscopic examination and culture of bacteria. Culture
Correspondence: Hassan Al Bisher, P.0. Box 6699, 31982 Eastern Province, Saudi Arabia. E-mail: dr.bisherhassan@yahoo.com

Key words: primary tuberculosis, pleomorphic adenoma, parotid gland.

Received for publication: 2 February 2010.

Revision received: 16 March 2010.

Accepted for publication: 17 March 2010.

This work is licensed under a Creative Commons Attribution 3.0 License (by-nc 3.0).

CC Copyright H. Al Bisher et al., 2010

Licensee PAGEPress, Italy

Infectious Disease Reports 2010; 2:e6

doi:10.4081/idr.2010.e6

of mycobacterial tuberculosis can take up to eight weeks; however, in $10-20 \%$ of cases, the bacillus is not successfully cultured..$^{10}$ The definite diagnosis of tuberculosis is isolation and identification of mycobacteria from the diag-
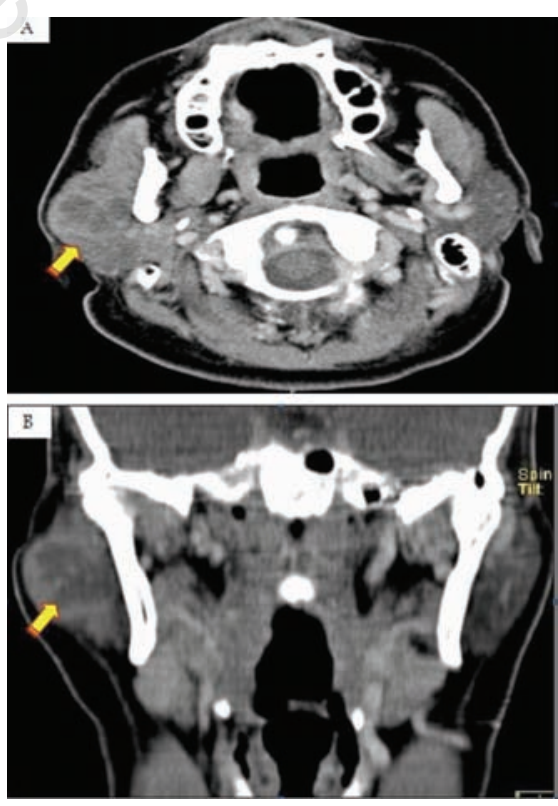

Figure 1. (A) and (B) CT scans indicating a heterogeneous mass (arrows) confined to the right parotid gland with no extensions to adjacent structures.

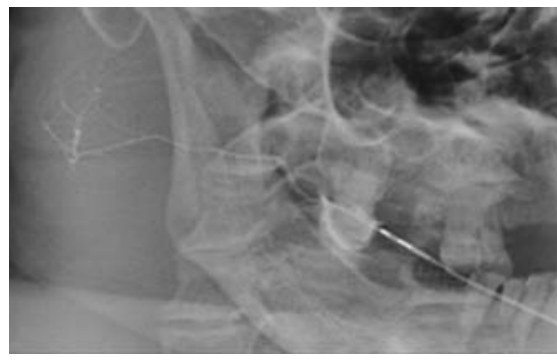

Figure 2. Normal right parotid sialogram. 
Table 1. Literature review of tuberculosis within a parotid tumor.

\begin{tabular}{|c|c|c|c|c|c|c|}
\hline Authors & Sex & Age & Tumor & Other focus of TB & Mycobacterium culture & PCR \\
\hline Owen TK' 1946 & $\mathrm{~F}$ & 60 & Adenolymphoma & -ve & -ve & NA \\
\hline Henver EP'2 1950 & M & 64 & Adenolymphoma & - ve & - ve & NA \\
\hline Collins DA DA $^{12} 1953$ & M & 65 & Adenolymphoma & - ve & + ve & $\mathrm{NA}$ \\
\hline Shaw $\mathrm{HJ}^{13} 1956$ & M & 33 & Bilateral adenolymphoma & - ve & - ve & NA \\
\hline Yamada N ${ }^{14} 1993$ & $\mathrm{~F}$ & 72 & Adenolymphoma & - ve & - ve & $\mathrm{NA}$ \\
\hline Watanabe $^{15} 2001$ & $\mathrm{~F}$ & 75 & Warthin's tumor & Tuberculosis meningitis & NA & $+\mathrm{ve}$ \\
\hline Watanabe $^{15} 2001$ & M & 78 & Warthin's tumor & -ve & - ve & $+\mathrm{ve}$ \\
\hline Ozcan C 2008 & M & 53 & Warthin's tumor & -ve & NA & $+\mathrm{ve}$ \\
\hline Wen $\mathrm{YH}^{16} 2008$ & M & 81 & Warthin's tumor & Bilateral lung nodules & + ve & $\mathrm{NA}$ \\
\hline Our case 2010 & $\mathrm{~F}$ & 51 & Pleomorphic adenoma & -ve & $+\mathrm{ve}$ & $\mathrm{NA}$ \\
\hline
\end{tabular}

NA, not available; -ve, negative; +ve, positive; PCR, polymerase chain reaction.

nostic specimen, ${ }^{8,11}$ which is essential for drugsusceptibility testing. In our case, the pathological report suggested pleomorphic adenoma, but the culture showed mycobacterial tuberculosis. We were not able to identify any primary source of tuberculosis elsewhere. Nevertheless, the patient was started on antituberculosis therapy.

Tuberculosis infection of the parotid gland along with the existence of a benign parotid tumor is very rare and only nine cases have been reported in the literature (Table 1). Our case is the $10^{\text {th }}$ such recorded case. We concluded, therefore, that the coexistence of parotid tuberculosis along with a benign parotid tumor is an extremely rare condition, and requires a high index of suspicion and challenges the clinician in its diagnosis.

\section{References}

1. Frieden TR, Sterling TR, Munsiff SS, et al. Tuberculosis. Lancet 2003;362:887-99.

2. Kim YH, Jeong WJ, Jung KY, et al.
Diagnosis of major salivary gland tuberculosis; experience of eight cases and review of the literature. Acta Oto-Laryngol 2005; 125:1318-22.

3. Al-Serhani AM. Mycobacterial infection of the head and neck: presentation and diagnosis. Laryngoscope 2001;111:2012-6.

4. Prasad KC, Sreedharan S, Chakravarthy Y, et al. Tuberculosis in the head and neck, experience in India. J Laryngol Otol 2007; 121:979-85.

5. Frank J. Primary tuberculosis of the parotid gland. Ann Surg 1902;36:945-50.

6. Koç A, Cengíz K, Sengör A, et al. Tubercolosis of the Parotid Gland. Otolaryngol Head Neck Surg 2005;133:640.

7. Ozcan C, Apa DD, Aslan G, et al. Mycobacterium tuberculosis infection within parotid gland Warthin tumor. J Craniofac Surg 2008;19:1561-5.

8. Birkent H, Karahatay S, Akcam T, et al. Primary parotid tuberculosis mimicking parotid neoplasm: a case report. J Med Case Reports 2008;2:62.

9. Lee IK, Liu JW. Tuberculous parotitis: case report and literature review. Ann Otol Rhinol Laryngol 2005;114:547-51.
10. Andersen P, Munk ME, Pollock JM, et al. Specific immune-based diagnosis of tuberculosis. Lancet 2000;356:1099-104.

11. Aygenc E, Albayrak L, Ensari S. Tuberculous parotitis. Inf Dis Clin Prac 2002;11:555-7.

12. Collins DH, Shukcksmith HS. Tuberculosis of the Parotid. Adenolymphoma and lymph glands incorporating salivary duct. J Pathol Bacteriol 1968;66:399-405.

13. Shaw HJ, Friedmann I. Bilateral adeno lymphoma of the parotid salivary gland associated with tuberculosis. Br J Surg 1959;46:500-5.

14- Yamada N, Uchinuma E, Akio A. Tuberculoma in an adenolymphoma arising in the parotid gland: a case report. Kitasato Med 1996;26:99-101.

15. Watanabe M, Nakayama T, Koduka Y, et al. Mycobacterium tuberculosis infection within Warthin's tumor: report of two cases. Pathol Int 2001;51:797-801.

16. Wen YH, Chen PR, Wu HP. Case report tuberculosis infection within a Warthin's tumor of the parotid gland. Tzu Chi Med J 2008;20:4. 